\title{
甞十九第 入第誌雜學地
}

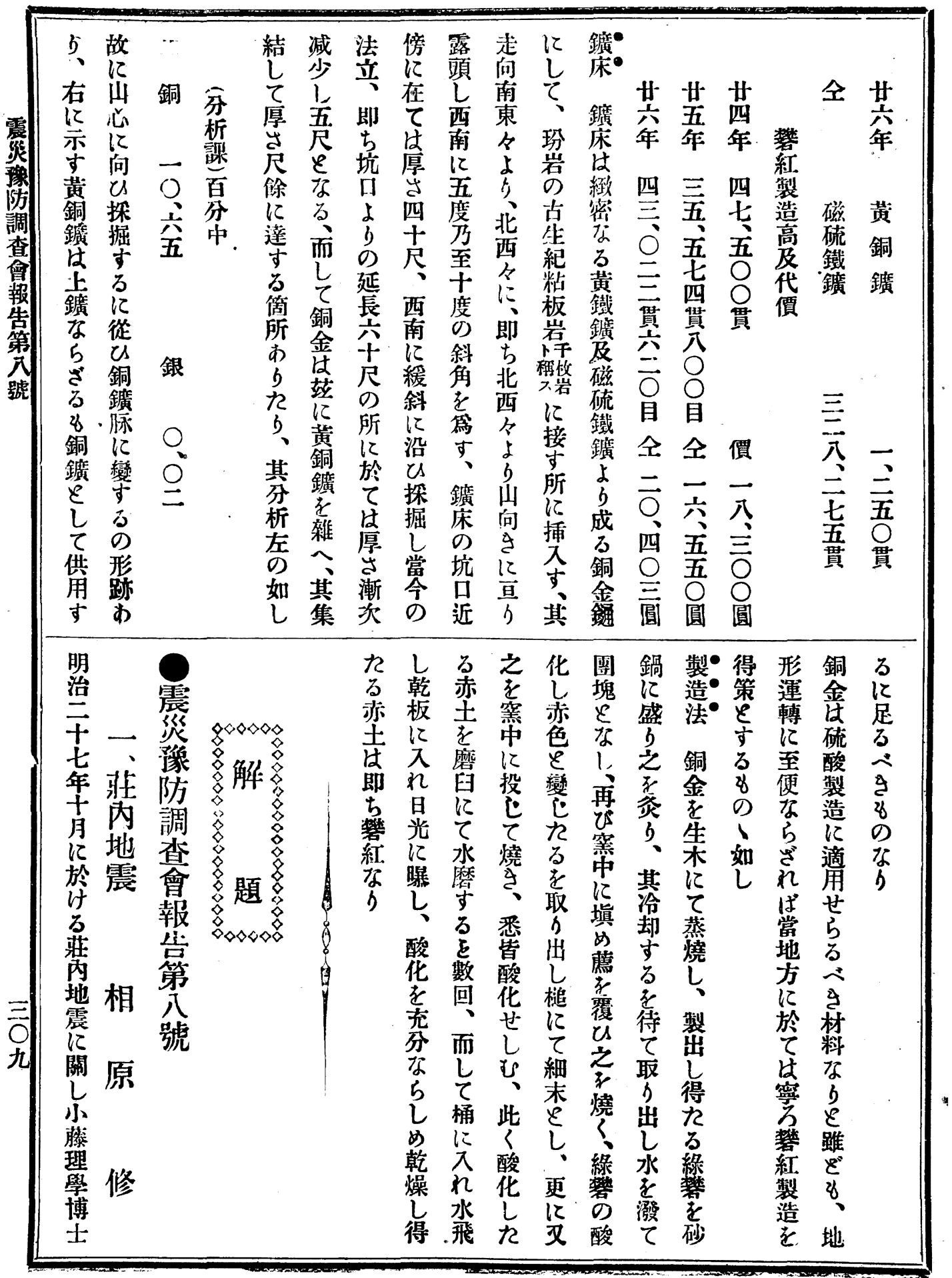




\section{召照日十月六年九十二治明}

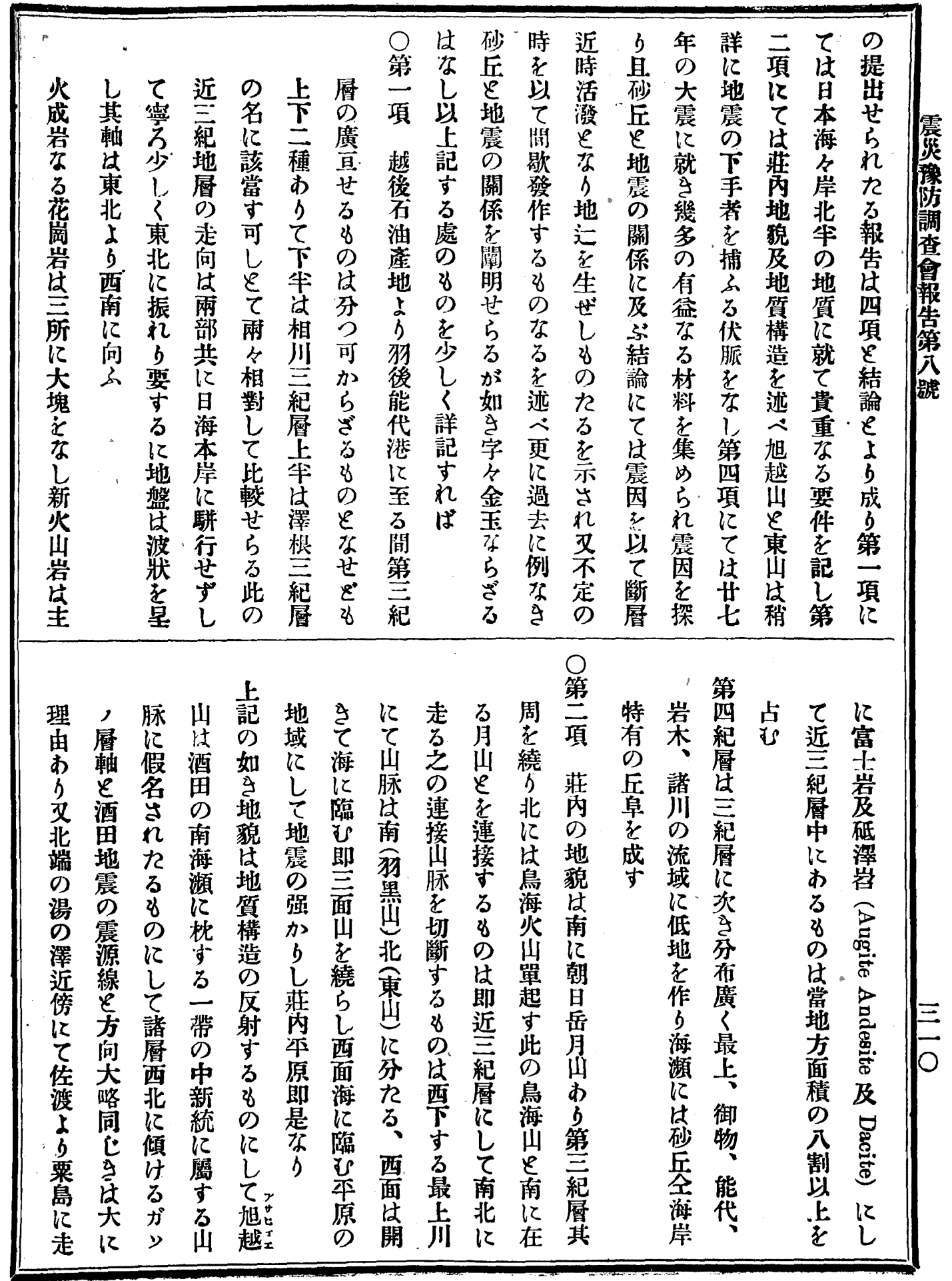


卷十九第集 八第誌雑學地

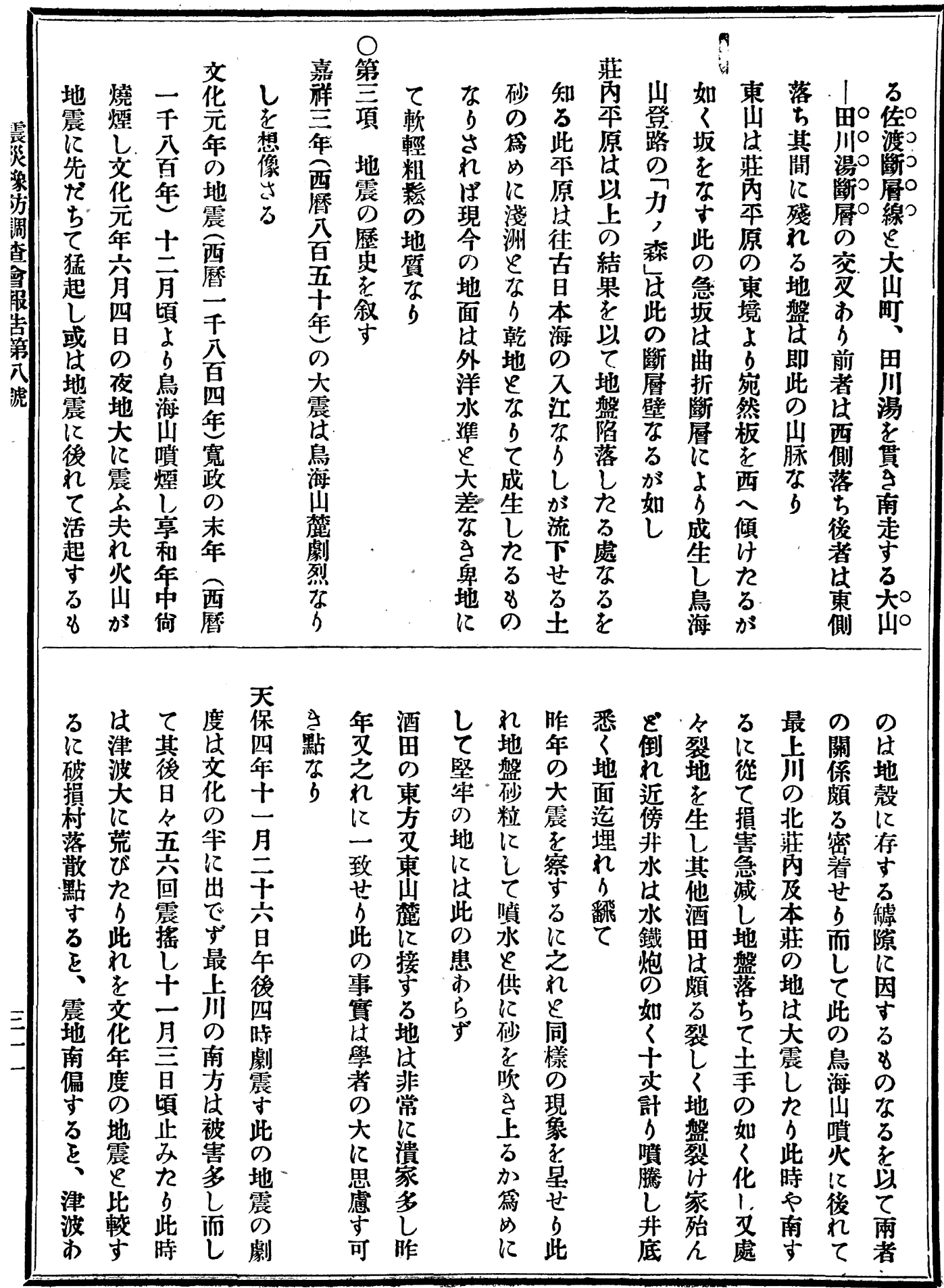


贫發日十月六年九十二治明

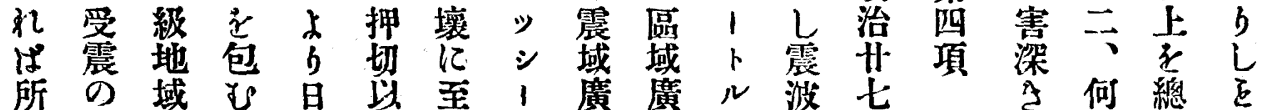

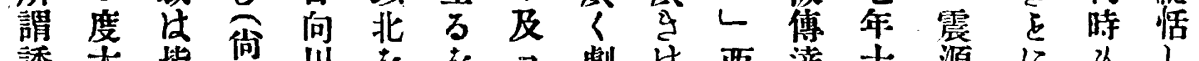

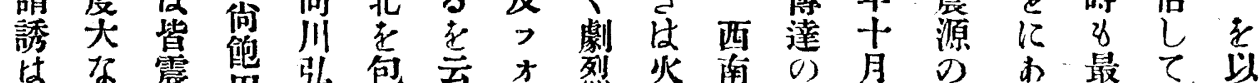

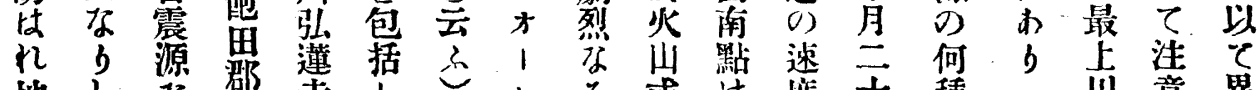

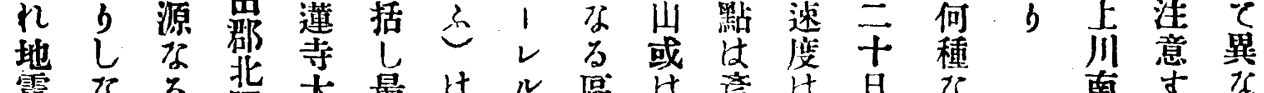

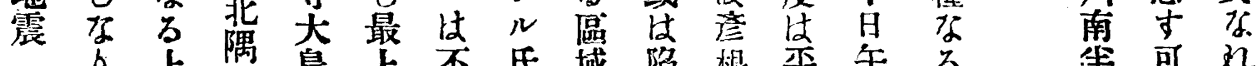

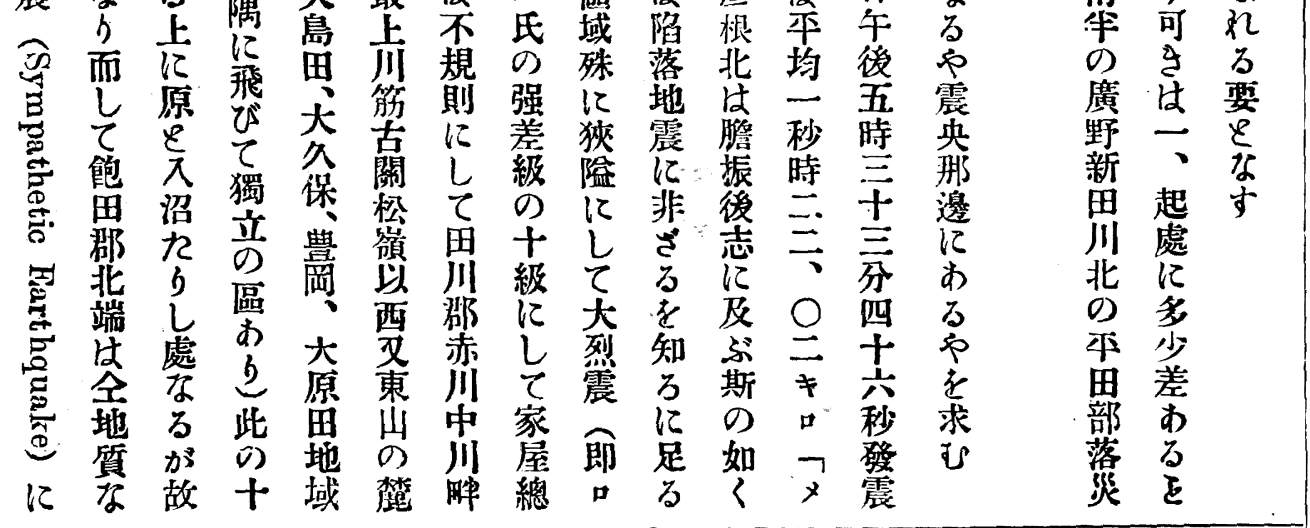

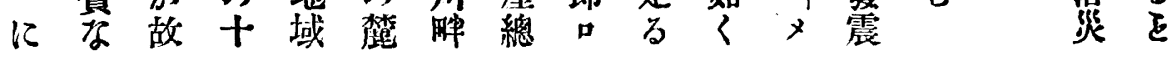

結

之砂洼てれ矢地の此割て震如旦屬

第劇 $\varepsilon$ 意 8 信破流割に名裂日烈〈向す

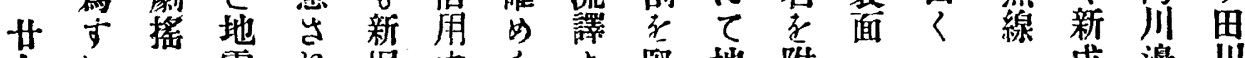

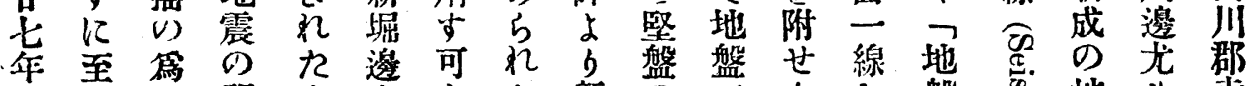

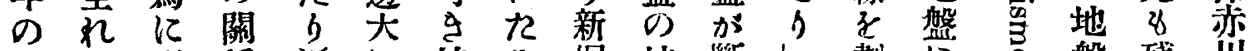

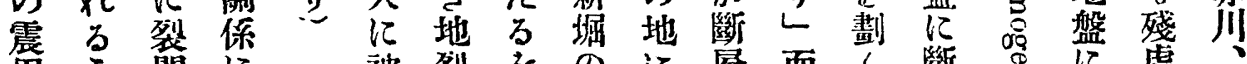

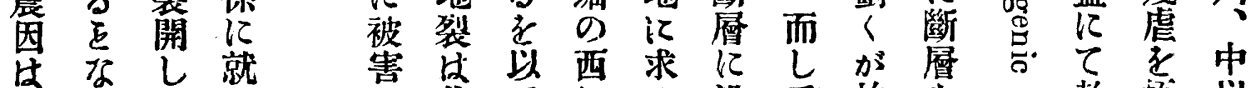

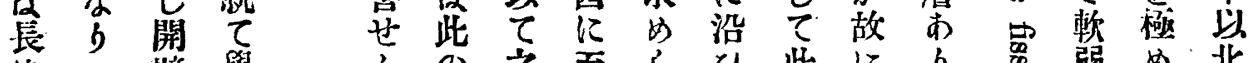

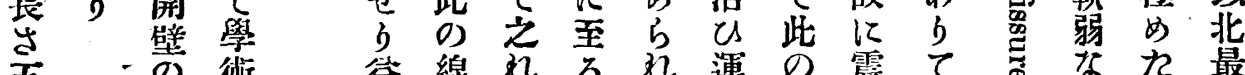

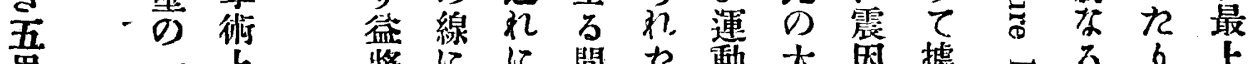

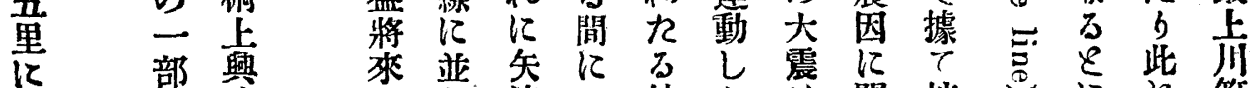

に部興 栍並矢に方

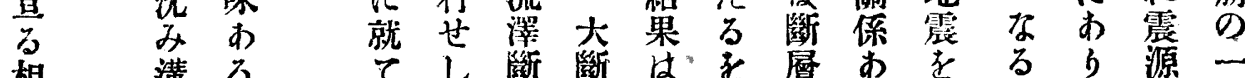

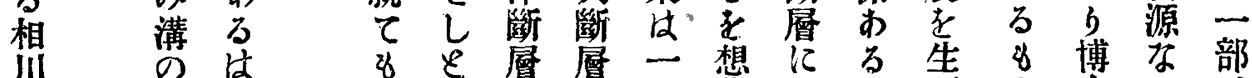

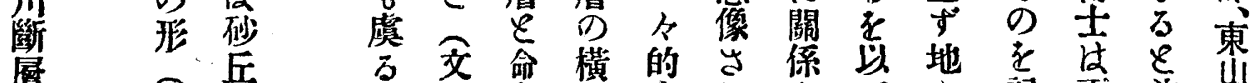

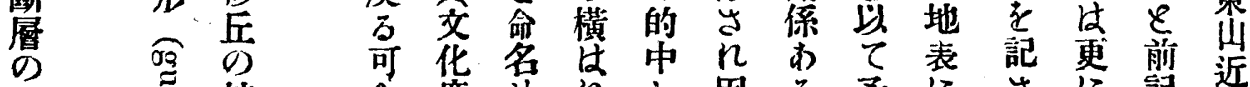

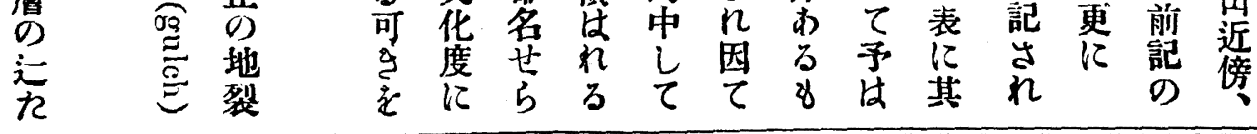




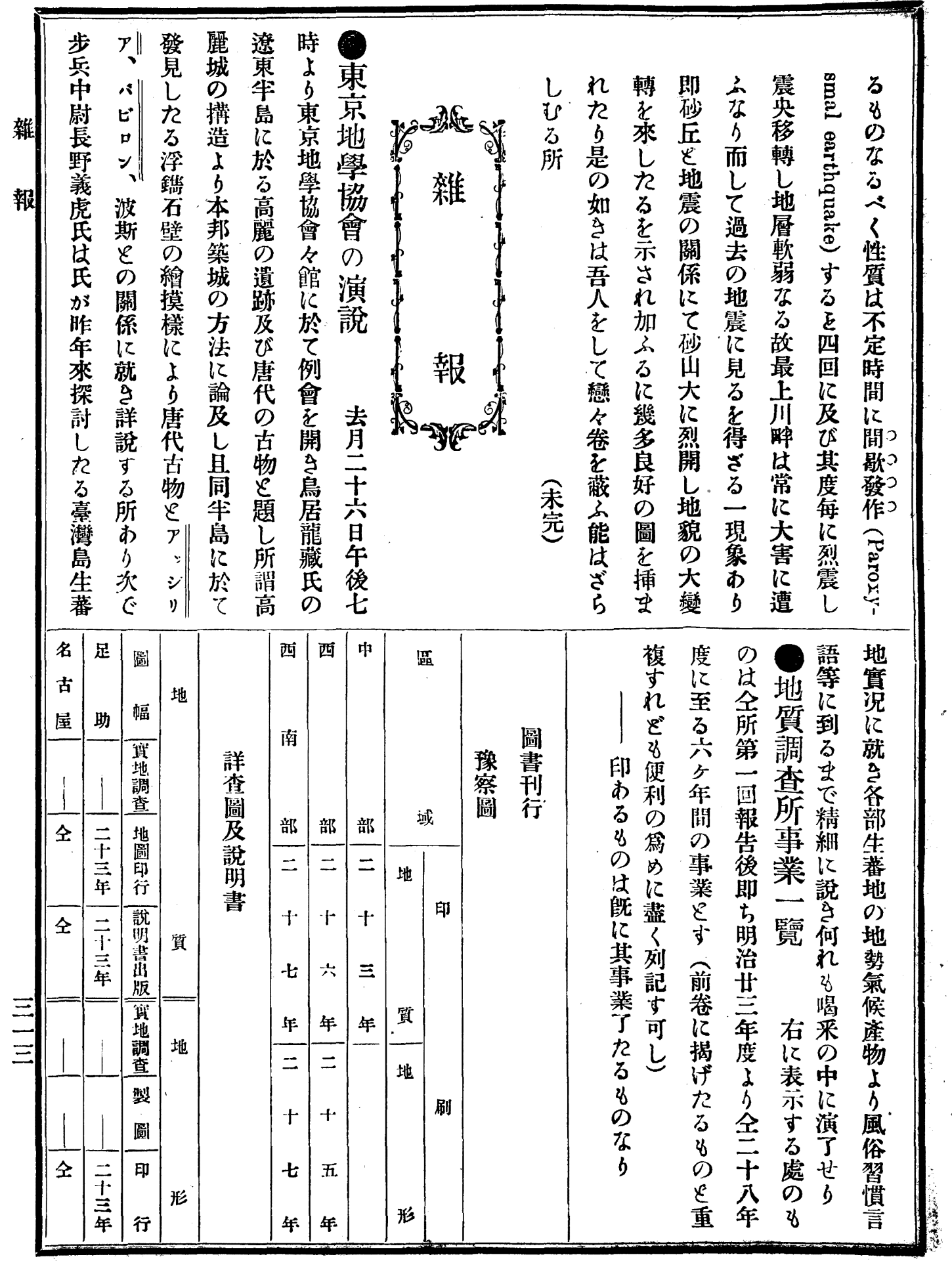

